\title{
Future Changes of Yamase Bringing Unusually Cold Summers over Northeastern Japan in CMIP3 Multi-Models
}

\author{
Hirokazu ENDO \\ Meteorological Research Institute, Tsukuba, Japan \\ (Manuscript received 26 April 2011, in final form 31 August 2011)
}

\begin{abstract}
Northeasterly winds blowing from high latitudes of the North Pacific in boreal summer, including the Sea of Okhotsk and the Bering Sea, are called the "Yamase" in Japanese. The Yamase brings unusually cold and cloudy summers over northeastern Japan, in contrast to climatological southeasterly winds, having great impact on agriculture and life in the region. Therefore, future changes of the Yamase, which may be caused by global warming, are a major concern.

This study is the first attempt to investigate future changes of Yamase frequency, which are defined using 10day mean surface winds, by analyzing eighteen coupled atmosphere-ocean general circulation model (AOGCM) experiments for May to August in the CMIP3 archives. We first assess present-day climate experiments (1981$2000,20 \mathrm{C} 3 \mathrm{M})$ and then examine the changes in future climate (2081-2100, SRES A1B scenario). In the presentday climate, an eighteen multi-model ensemble (MME18) mean modestly reproduces seasonal variation of the Yamase frequency, although each model generally underestimates the Yamase frequency compared to the reanalysis data and large differences are seen among the models. In the future climate, most models project increases of the Yamase frequency in August in contrast to decreases of the frequency in May, whereas projected frequency changes in June, July and May to August (MJJA) are inconsistent among the MME18. Inter-model comparison suggests that weakening of mean tropical circulation, including the Walker circulation, may contribute to the increased Yamase frequency in August. A projection employing only nine of the models with higher skill (MME9hi), based on a defined metric, is also tried. Negative anomalies in June over the Sea of Okhotsk and eastern Siberia in the mean sea level pressure field are contrasted with positive anomalies in July, which are unclear in the MME18 projections. In August, almost all the MME9hi project increase of the Yamase frequency, consistent with the MME18 projections.
\end{abstract}

\section{Introduction}

Northeasterly winds blowing from high latitudes of the North Pacific in boreal summer are called the "Yamase" in Japanese. The Yamase brings unusually cold and cloudy summers to northeastern Japan, in contrast to climatological southeasterly winds (Ninomiya and Mizuno 1985), having great impact on agriculture and life in the region. Therefore, future changes of the Yamase, which may be

Corresponding author: Hirokazu Endo, Climate Research Depertment, Meteorological Research Institute, 1-1 Nagamine, Tsukuba, Ibaraki, 305-0052, Japan. E-mail: hendo@mri-jma.go.jp

(C) 2012, Meteorological Society of Japan caused by global warming, are a major concern across the region.

The origin of the Yamase is the cold polar maritime air mass formed over the high latitudes of North Pacific, including the Sea of Okhotsk and the Bering Sea (Ninomiya and Mizuno 1985; Kodama 1997). In boreal summer, the Yamase sometimes blows toward northeastern Japan, typically under a surface pressure pattern in which an anticyclone, called the Okhotsk high, stagnates around the Sea of Okhotsk, and a front and/or a cyclone stay over southern coast of Japan or the ocean east of Japan (Ninomiya and Mizuno 1985; Kanno 1997), as shown in Fig. 1a. This anomalous pressure pattern is often accompanied by a blocking 
(a)

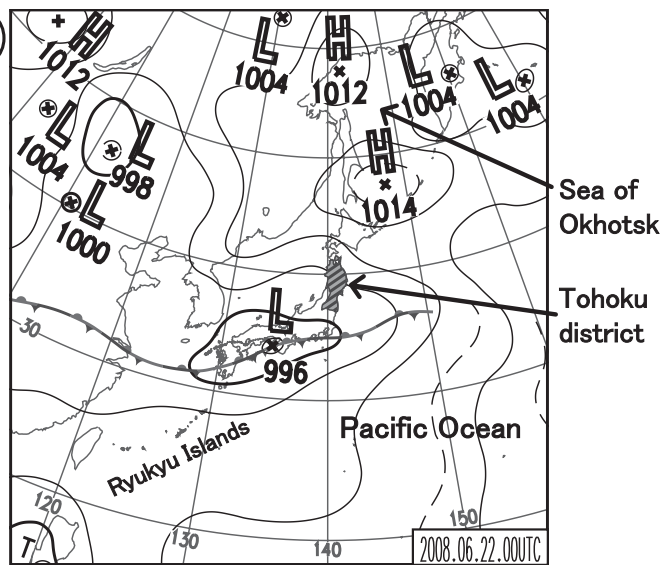

(b)

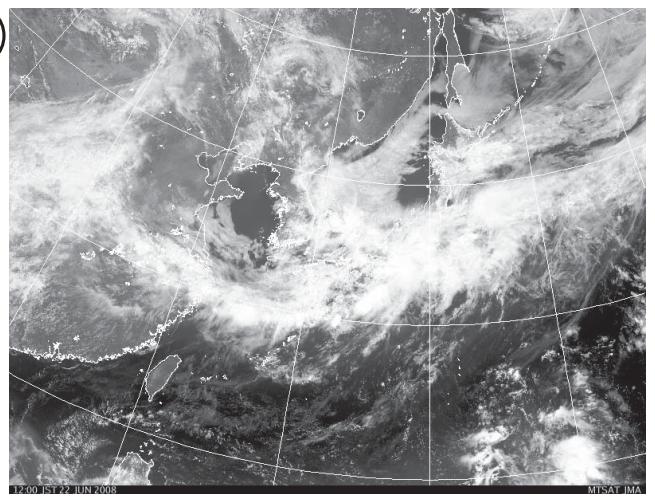

Fig. 1. A typical Yamase event on 22 June 2008. (a) The surface weather chart for 00UTC (09JST) on 22 June 2008 produced by Japan Meteorological Agency. (b) The MTSAT visible image at 03UTC (12JST) on 22 June 2008.

flow in the upper troposphere and sometimes persists for a week or more (Nakamura and Fukamachi 2004). Air masses transported southward by the Yamase become wet and are usually accompanied by marine boundary layer clouds owing to an abundant supply of moisture from the ocean as the air mass approaches Japan (Kodama 1997; Fig 1b). Thus, continuous Yamase occurrences bring anomalously cold and cloudy summers over northeastern Japan. In interannual time scales, the anomalous large-scale circulation providing background for frequent Yamase occurrence is formed not only by extra-tropical factors such as eastward propagation of a stationary Rossby wave along the polar frontal jet (Nakamura and Fukamachi 2004; Tachibana et al. 2004; Wakabayashi and Kawamura 2004) but also by tropical factors such as El Nino/ Southern oscillation (ENSO) with both simultane- ous and lagged effects (Wang et al. 2001; Kanno 2004; Tachibana et al. 2004; Yasunaka and Hanawa 2006).

For predicting climate changes caused by anthropogenic forcing, multi-model ensemble (MME) methods utilizing coupled atmosphere-ocean general circulation model (AOGCM) outputs have been widely applied because the MME method is effective for improving the projection due to reduction of biases and uncertainties of individual models (Giorgi and Mearns 2002; Min et al. 2004) and for estimation of the robustness of the projected changes (Kitoh and Uchiyama 2006; Inoue and Ueda 2011). For the East Asian summer, several studies have projected future changes by the anthropogenic forcing based on the MME. Min et al. (2004) applied weighted MME averages based on each model's skill to simulate present climate to Phase 2 of the Coupled Model Intercomparison Project (CMIP2) models, and obtained increased precipitation and raised temperature over East Asia in the future climate. Kimoto (2005) revealed increased Meiyu-Changma-Baiu activity associated with the strengthening of anticyclonic cells to the south and north of East Asia, based on a simple MME average of multiple AOGCM experiments in the CMIP3 datasets. Kitoh and Uchiyama (2006) found a delay in the early summer rain withdrawal over the region extending from Taiwan to the Ryukyu Islands to the south of Japan, through the weighted MME average of multiple AOGCM simulations in the CMIP3 archives.

In addition to the AOGCMs, high-resolution atmospheric general circulation models (AGCM) and regional climate models (RCM) have been employed for use in the climate change study in order to derive information about extreme phenomena and regionally localized phenomena. Kusunoki et al. (2006) and Kusunoki and Mizuta (2008) investigated future changes in the Baiu rain band based on 20-km mesh AGCM experiments, and derived results consistent with the above findings. Endo (2008) investigated a 20-km mesh RCM simulation for Japan (Kurihara et al. 2005), nested by MRI-CGCM2 under the SRES A2 scenario, focusing on the Yamase phenomenon. He found that Yamase-type low temperature events, defined by an east-west surface temperature difference over the northern Tohoku district, increase from late July to early August in the future climate.

These previous studies hint that the Yamase might be influenced by global warming, however, 
the Yamase has not yet been directly investigated in the AOGCM simulations. Therefore, in this study, we first assess the Yamase in present-day climate experiments, and then examine its changes in future climate experiments based on the MME in the CMIP3 model outputs, and then discuss factors affecting the projected changes.

\section{Data and definition of Yamase}

We analyze daily outputs for the present-day (1981-2000) under the 20C3M simulation and for the end of the twenty-first century (2081-2100) under the SRES A1B scenario simulation in the CMIP3 dataset. We select the models that have daily surface wind and sea level pressure data archives for those periods. The following eighteen AOGCMs are included in the analysis: CGCM3.1(T47), CGCM3.1(T63), CNRM-CM3, CSIRO-MK3.0, CSIRO-MK3.5, GFDL-CM2.0, GFDL-CM2.1, GISS-AOM, GISS-ER, FGOALSg1.0, INM-CM3.0, MIROC3.2(hires), MIROC3.2(medres), ECHAM5/MPI-OM, MRI-CGCM2.3.2, INGV-ECHAM4, IPSL-CM4 and ECHO-G. Only one member (the first member) of each model is used, even for models with multi-member data available. The daily data are first interpolated into common $2.5^{\circ}$ latitude by $2.5^{\circ}$ longitude horizontal grids, and then temporally averaged. Three models \#16, \#17 and \#18 (ID numbers shown in Table 1) use a 360 day annual calendar, and therefore we assume the three models have 30 days in each month. For evaluation of the model outputs, JRA-25 reanalysis data (Onogi et al. 2007) is used. The analysis is carried out for May to August, which corresponds to typical Yamase season (Kanno 1993; Takai et al. 2006).

In this study, the Yamase is defined as a northeasterly wind blowing over the area east of northeastern Japan, based on surface wind data averaged over 10-day or 11-day segments (i.e., averaged over the 1 st to 10 th, 11 th to 20 th, and 21 st to 30 th (or $31 \mathrm{st}$ ) of each month). The daily data are first temporally averaged over the 10-day or 11-day segments in the 20 years (1981-2000 and 2081-2100) and then spatially averaged over $40^{\circ} \mathrm{N}-45^{\circ} \mathrm{N}$ and $142.5^{\circ} \mathrm{E}-155^{\circ} \mathrm{E}$. Then, using the area-averaged value, the frequency of northeasterly wind events (i.e. zonal wind component is easterly and meridional wind component is northerly) is counted. The 10-day mean surface wind data are used in order to exclude northeasterly wind events accompanying fast-passing synoptic disturbances and to focus on the Yamase events caused by the Okhotsk high. The Okhotsk high has longer time scales than the synoptic disturbances because it is developed by a quasi-stationary blocking ridge in the upper troposphere (Nakamura and Fukamachi 2004).

\section{Present-day climate simulation}

Before the Yamase simulated in the models is assessed, the model performances in reproducing the climatological mean sea level pressure (MSLP) patterns of the present-day climate are first evaluated. Figure $2 \mathrm{a}$ shows MSLP for the JRA-25 and the eighteen multi-model ensemble (MME18) mean and the bias of the MME18 mean over the northwestern Pacific from May to August. The MME18 mean realistically simulates the Pacific high and its seasonal evolution on a broad scale: that is, a high pressure cell prevails over the Pacific, and its ridge axis gradually migrates northward from May to August. However, the MME18 mean shows a systematic bias toward a strong Pacific high and a weak Okhotsk high, which cause a bias toward southwesterly winds around Japan. It is also noted that the MME18 mean does not show the relatively low pressure zone over southern Japan seen in the JRA-25 in June and July, which would indicate a weaker Baiu rain band.

In order to objectively quantify each model's performance in reproducing the MSLP pattern, we introduced the skill score $(S S)$ proposed by Taylor (2001), which has been widely employed to evaluate the performance of climate model. The skill score $S S$ is defined as follows:

$$
S S=\frac{4(1+R)}{(S D R+1 / S D R)^{2}\left(1+R_{0}\right)} .
$$

Where $R$ is the spatial correlation coefficient between observation and simulation, $S D R$ is the spatial standard deviation of the simulation divided by that of the observation, and $R_{0}$ is the maximum correlation attainable. Here we assumed $R_{0}=1$. $S S$ evaluates both the spatial correlation coefficient and the spatial standard deviation. The $S S$ approaches 1.0 in a perfect simulation. $S S$ s of the MSLP (SS_MSLP) over the northwestern Pacific $\left(120^{\circ} \mathrm{E}-170^{\circ} \mathrm{E}, \quad 25^{\circ} \mathrm{N}-60^{\circ} \mathrm{N}\right)$ are calculated for each model (Table 1).

Figure 2c shows the MSLP for JRA-25 and the respective models in June, when the Yamase blows the most frequently (as shown in the next paragraph). The statistics used in the right side of 


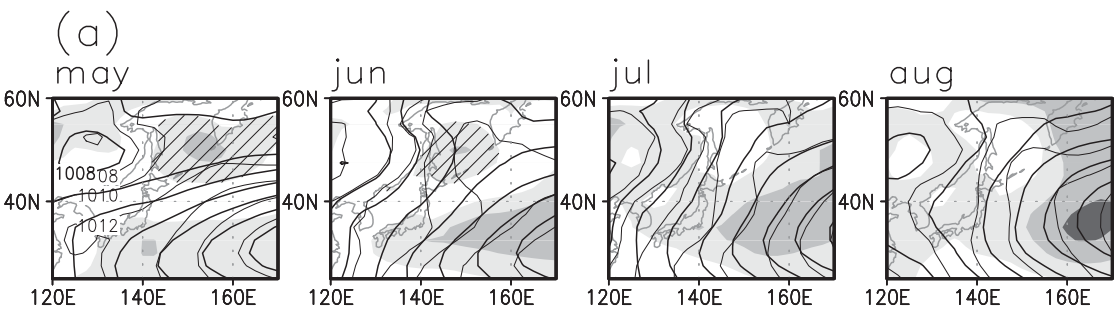

(b)

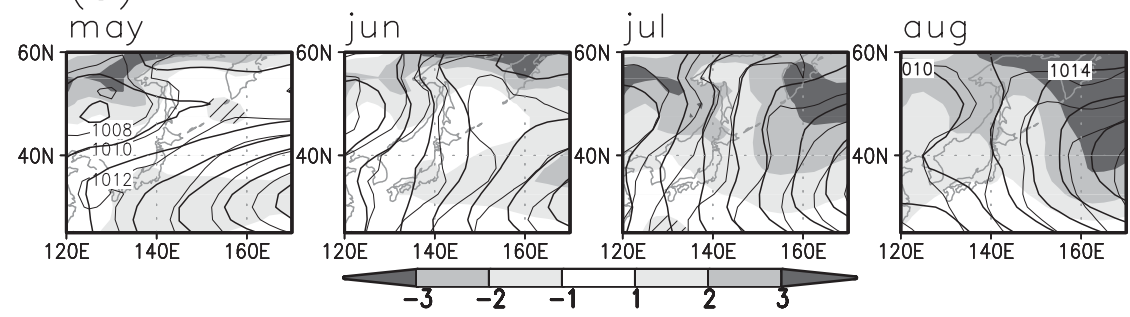

(C)
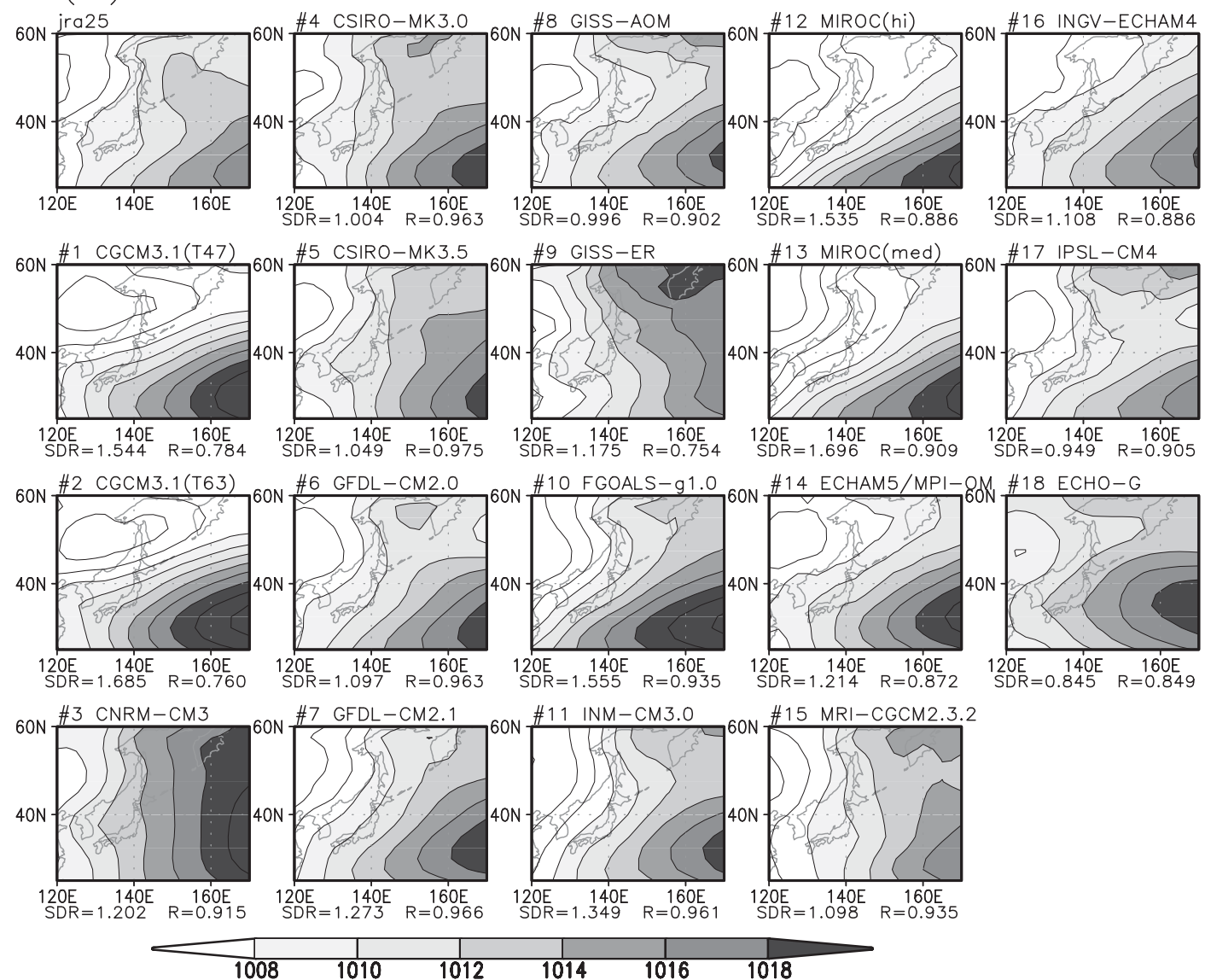

Fig. 2. (a) Climatological mean sea level pressure in JRA-25 (thin contours) and the MME18 mean (thick contours) and bias of the MME18 (shading) from May to August in the present-day climate (1981-2000). Negative biases are hatched. (b) same as (a) except for MME9hi. (c) Climatological mean sea level pressure for JRA-25 and all models in June in the present climate. The contour interval is $2 \mathrm{hPa}$. 
Table 1. Yamase frequency (per 20 years), skill scores for the spatial pattern of the mean sea level pressure $\left(S S \_M S L P\right)$ over the northwestern Pacific $\left(25^{\circ}-60^{\circ} \mathrm{N}, 120^{\circ}-170^{\circ} \mathrm{E}\right)$, defined by Eq. (1), and the $S S$ metric defined in this study for the 18 models. The Yamase frequency for JRA-25, MME18 average and MME9hi average are shown in the lower column. The SS_MSLP are validated against the JRA-25. Notice that the Yamase frequencies are counted from 60 segments ( 3 segments $\times 20$ years) in each month in the present climate (1981-2000). See text for definition of the Yamase frequency and the metric. Asterisks $\left(^{*}\right)$ and sharps (\#) on the left side of the table indicate the 9 higher skill models (MME9hi) and the 14 models (MME14) with a negative sign of $\Delta \mathrm{EQ}-\mathrm{SOI}$, respectively.

\begin{tabular}{|c|c|c|c|c|c|c|c|c|c|c|c|}
\hline \multirow[b]{2}{*}{ ID } & \multirow[b]{2}{*}{ Model } & \multicolumn{5}{|c|}{ Yamase frequency (per 20 years) } & \multicolumn{4}{|c|}{ MSLP skill score } & \multirow{2}{*}{$\frac{\text { Metric }}{\mathrm{JJ}}$} \\
\hline & & May & Jun & Jul & Aug & MJJA & May & Jun & Jul & Aug & \\
\hline 1 & CGCM3.1(T47) & 2 & 3 & 5 & 4 & 14 & 0.753 & 0.743 & 0.832 & 0.783 & -1.305 \\
\hline \#2 & CGCM3.1(T63) & 2 & 0 & 1 & 0 & 3 & 0.709 & 0.678 & 0.785 & 0.720 & -2.272 \\
\hline$* \# 3$ & CNRM-CM3 & 8 & 9 & 8 & 10 & 35 & 0.951 & 0.926 & 0.943 & 0.832 & 0.536 \\
\hline *\#4 & CSIRO-MK3.0 & 5 & 13 & 8 & 12 & 38 & 0.977 & 0.982 & 0.957 & 0.865 & 1.159 \\
\hline$* \# 5$ & CSIRO-MK3.5 & 3 & 15 & 11 & 10 & 39 & 0.896 & 0.985 & 0.942 & 0.827 & 1.573 \\
\hline$* \# 6$ & GFDL-CM2.0 & 6 & 10 & 7 & 4 & 27 & 0.908 & 0.973 & 0.983 & 0.883 & 0.861 \\
\hline$* \# 7$ & GFDL-CM2.1 & 3 & 6 & 7 & 7 & 23 & 0.958 & 0.928 & 0.986 & 0.923 & 0.293 \\
\hline$* \# 8$ & GISS-AOM & 1 & 7 & 8 & 5 & 21 & 0.804 & 0.951 & 0.968 & 0.945 & 0.478 \\
\hline$* 9$ & GISS-ER & 11 & 20 & 4 & 4 & 39 & 0.777 & 0.855 & 0.957 & 0.888 & 0.232 \\
\hline \#10 & FGOALS-g1.0 & 3 & 4 & 18 & 11 & 36 & 0.786 & 0.801 & 0.911 & 0.773 & -0.672 \\
\hline 11 & INM-CM3.0 & 4 & 11 & 3 & 5 & 23 & 0.837 & 0.898 & 0.902 & 0.852 & 0.020 \\
\hline$\# 12$ & MIROC3.2(hires) & 5 & 8 & 5 & 4 & 22 & 0.785 & 0.789 & 0.813 & 0.690 & -0.691 \\
\hline \#13 & MIROC3.2(medres) & 6 & 8 & 2 & 0 & 16 & 0.787 & 0.731 & 0.799 & 0.602 & -1.209 \\
\hline \#14 & ECHAM5/MPI-OM & 6 & 7 & 4 & 2 & 19 & 0.959 & 0.901 & 0.943 & 0.918 & -0.052 \\
\hline$* \# 15$ & MRI-CGCM2.3.2 & 6 & 14 & 18 & 19 & 57 & 0.984 & 0.959 & 0.893 & 0.692 & 0.698 \\
\hline 16 & INGV-ECHAM4 & 2 & 4 & 6 & 9 & 21 & 0.882 & 0.933 & 0.969 & 0.909 & -0.031 \\
\hline$* \# 17$ & IPSL-CM4 & 10 & 14 & 19 & 15 & 58 & 0.692 & 0.950 & 0.919 & 0.887 & 0.635 \\
\hline \multirow[t]{4}{*}{ \#18 } & ECHO-G & 6 & 5 & 7 & 10 & 28 & 0.899 & 0.899 & 0.887 & 0.865 & -0.253 \\
\hline & MME18 & 4.9 & 8.8 & 7.8 & 7.3 & 28.8 & & & & & \\
\hline & MME9hi & 5.9 & 12.0 & 10.0 & 9.6 & 37.4 & & & & & \\
\hline & JRA-25 & 7 & 16 & 12 & 8 & 43 & & & & & \\
\hline
\end{tabular}

Eq. (1) are shown at the bottom of each panel in Fig. 2c. In the JRA-25, the Pacific high prevails over the subtropical Pacific and the high pressure area extends into the Sea of Okhotsk, which corresponds to the Okhotsk high. In the model results, on the other hand, the Okhotsk high tends to be weak and the Pacific high tends to be strong, as indicated by large spatial standard deviations of the MSLP. In fact, 15 out of the 18 models show SDR values lager than 1.0 in June. In particular, models $\# 1, \# 2, \# 10, \# 12$, and \#13 have a large SDR of more than 1.5 because they simulate a weak Okhotsk high and a strong Pacific high, resulting in anomalous southwesterly winds around Japan. These models with larger $S D R$ also have lower SSs (Table 1). Of the 18 models, 14 models in May, 14 in July and 17 in August show a positive bias in the $S D R$. In addition, it is noted that the models tend to reproduce the Okhotsk high over the northern part of the Sea of Okhotsk, whereas the observation shows it over the central Sea of Okhotsk.

We next assess the Yamase frequency reproduced by the models. Table 1 summarizes the frequency in each model and in JRA-25 for May to August. In JRA-25, the Yamase blows most frequently in June. The winds occurred 16 times in the 20 years for 1981 to 2000 in June, corresponding to a $27 \%$ occurrence ratio ( $=16$ occurrences/( 3 segments $\times$ 20 years)), 12 times in July, 8 times in August, and 7 times in May. The MME18 mean reproduces this seasonal variation, although its amplitude is less than that in the observed data. Comparing the frequencies between JRA-25 and each model, most models underestimate the Yamase frequency, especially in June and July, and there are large differences among the models. Only model \#9 overestimates the frequency in June; models \#10, \#15 and \#17 overestimate it in July; and models \#15 and \#17 overestimate the total frequency from 


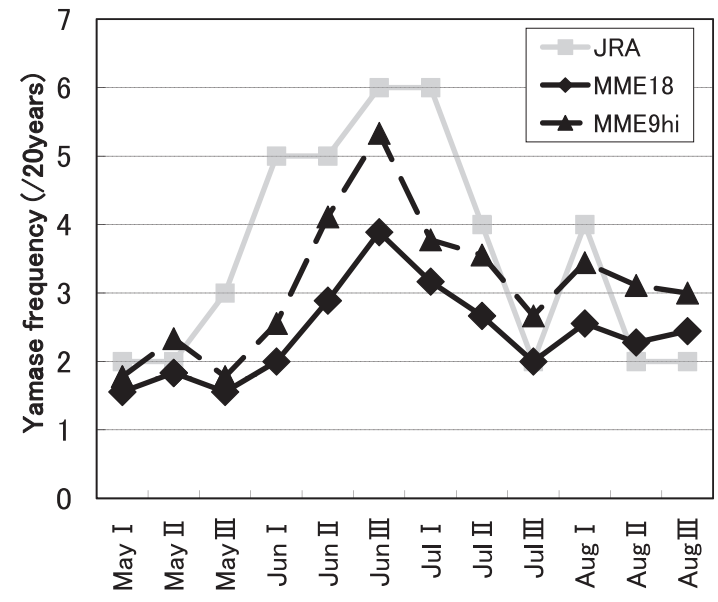

Fig. 3. Seasonal variation of the climatological mean Yamase frequency (per 20 years) for JRA-25 (gray), the MME18 mean (black), and the MME9hi mean (dashed black) by 10-day segments. The Yamase frequency is obtained in the present climate (1981-2000). Key: I = 1st to 10 th, II = 11 th to 20 th, and III $=21$ st to 30 th (or

May to August (MJJA). Moderate inter-model correlations are seen between the error of the Yamase frequency and the $S S \_$MSLP over the northwestern Pacific, with correlation coefficients of -0.49 , $-0.65,-0.63$ and -0.59 for May, June, July, and August, respectively.

Figure 3 shows the climatological seasonal variation in the Yamase frequency by 10- (or 11-) day segments. Similar to the JRA-25, the MME18 mean frequency increases in June and July, peaking in late June. According to Kanno (1993), who defined "Yamase days" based on daily surface wind and temperature observed at Hachinohe station, on the Pacific side of northern Japan, the occurrence ratio of the Yamase is more than 30\% from late June to mid July, and the Yamase is most frequent $(37 \%)$ in late June. Compared to their result, the seasonal evolution in the Yamase occurrence defined in this study is similar to theirs, although the occurrence is slightly less.

\section{Future changes}

\subsection{Multi-model ensemble of eighteen models}

Figure 4a shows future changes of the MSLP ( $\triangle$ MSLP) in MME18 in the future climate (20812100), compared with the present-day climate (1981-2000), for May to August. In order to dis- play the robustness of the projection, the number of models showing a positive change is indicated by the color scale, in which ' 18 ' means that all models project a positive $\triangle \mathrm{MSLP}$, and ' 0 ' means that all models project a negative $\triangle$ MSLP. In Fig. $4 \mathrm{a}$, most models show negative anomalies over high latitudes in May and positive anomalies over the tropical western Pacific from July to August. In addition, negative anomalies prevail over midlatitudes $\left(30^{\circ} \mathrm{N}-40^{\circ} \mathrm{N}\right)$ of the Pacific from June to August, and a north-south dipole pattern prevails over the Pacific in August; most of these anomalies, however, are not very consistent among the models. Robust future change is not projected around the Sea of Okhotsk in June and July, when the quasi-stationary anticyclone (Okhotsk high) sometimes appears over that region, continuously causing the Yamase over northeastern Japan in the observation.

Figure 5 shows future changes in the Yamase frequency by comparing the future climate (20812100) under the SRES A1B with the present-day climate (1981-2000) under the 20C3M. Although there are large differences among the models, most models project increased Yamase frequency in August in contrast to decreased Yamase frequency in May. On the contrary, the projected changes in the Yamase frequency in June, July and MJJA are inconsistent among the models. These future changes of the Yamase frequency are generally consistent with wind changes inferred from the projected MSLP changes shown in Fig. 4a.

We explore tropical factors affecting the projected changes of the Yamase frequency by multimodel inter-comparison. According to IPCC (2007), multi-AOGCM averages project a weak shift towards conditions which are described as "El Nino-like", with sea surface temperatures in the central and eastern equatorial Pacific warming more than those in the western Pacific, with an eastward shift in the distribution of precipitation and with weakened tropical circulation. This El Nino-like mean state change is considered to be attributed to the general reduction in tropical circulations resulting from the increased dry static stability in the tropics (Knutson and Manabe 1995). Kitoh and Uchiyama (2006) and Kusunoki et al. (2006) suggest that the El Nino-like change prolongs the Baiu season due to increased moisture flux from a strengthened subtropical high in the tropical western Pacific. We investigate possible effects of such tropical change on the projected changes of the 
(a) MME18
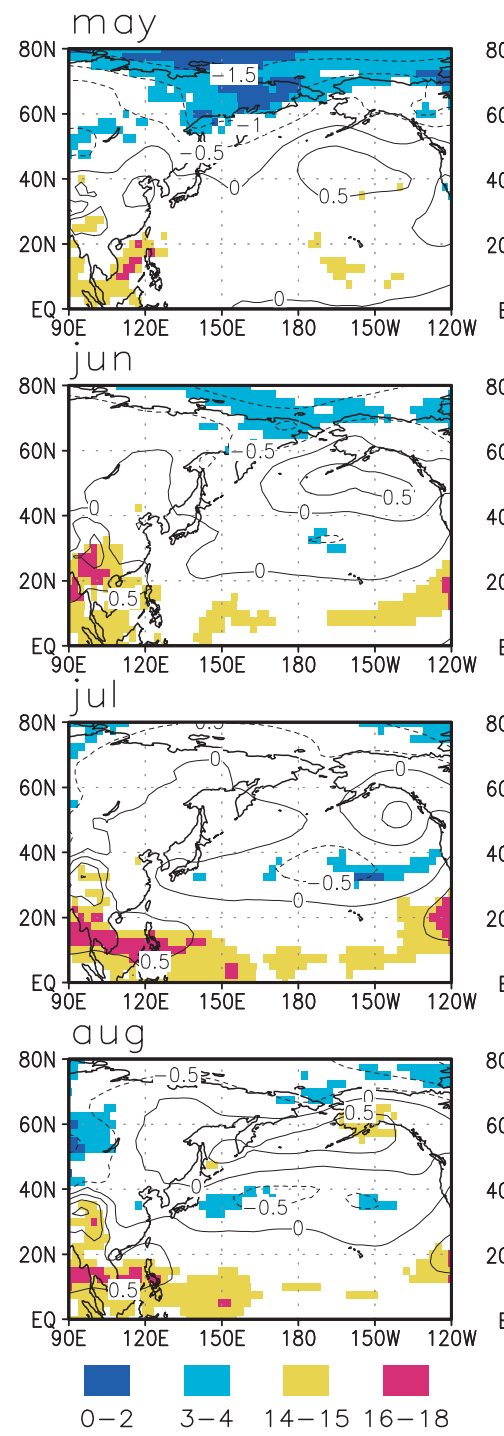

(b) $M M E 14$
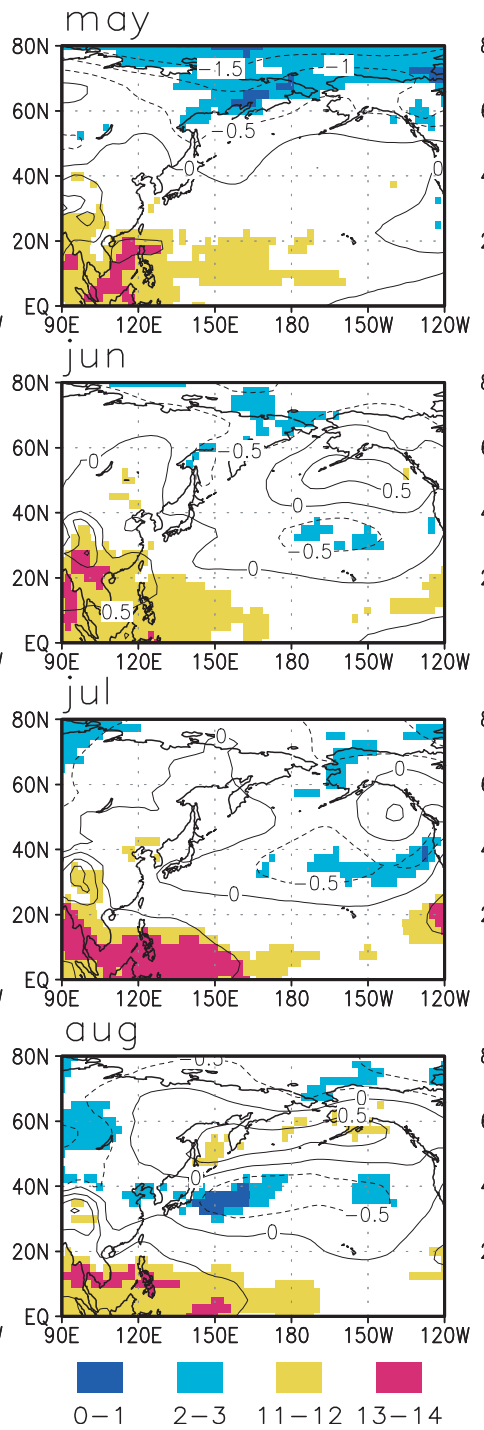

(c) MME9hi
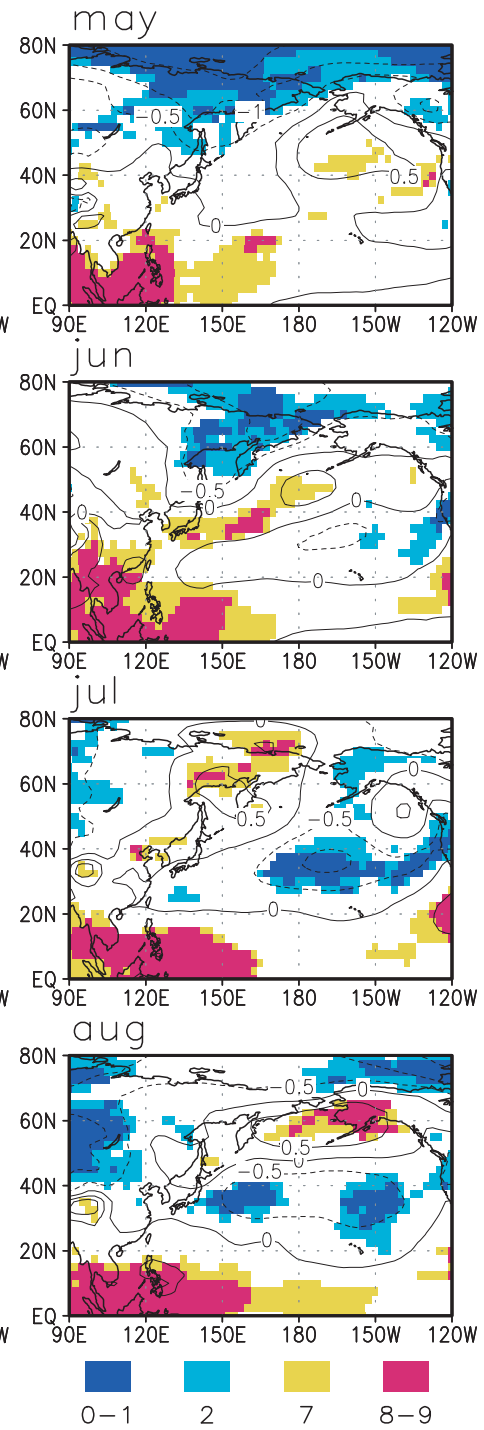

Fig. 4. Future changes of the mean sea level pressure (hPa) in (a) MME18, (b) MME14 and (c) MME9hi for May to August in the future climate (2081-2100) of the SRES A1B experiments compared with the present-day climate (1981-2000) of the 20C3M experiments. Contours show the changes in the MME mean; the contour interval is $0.5 \mathrm{hPa}$. Shading shows the number of models with a positive change. Red (yellow) shading indicates that the fraction of the models projecting a positive change is approximately $90 \%(80 \%)$ or higher. Dense blue (light blue) shading indicates that fraction of the models projecting a negative change is approximately $90 \%(80 \%)$ or higher.

Yamase occurrence, employing an equatorial SLP index, as defined by Vecchi et al. (2006), to roughly assess change of the Walker circulation. This index denoted as EQ-SOI is defined as the difference in the MSLP between the eastern Pacific $\left(5^{\circ} \mathrm{S}-5^{\circ} \mathrm{N}\right.$, $\left.160^{\circ} \mathrm{W}-80^{\circ} \mathrm{W}\right)$ and the Indo-West Pacific $\left(5^{\circ} \mathrm{S}-\right.$ $\left.5^{\circ} \mathrm{N}, \quad 80^{\circ} \mathrm{E}-160^{\circ} \mathrm{E}\right) . \quad \Delta \mathrm{EQ}-\mathrm{SOI}$ denotes future changes in the index. Figure $4 \mathrm{~b}$ is the same as Fig. 4a except it shows composite maps of only the 14 models (MME14) with a negative $\triangle E Q-S O I$ for the June-August mean (JJA). In MME14, negative anomalies are dominant over the mid-latitudes of the Pacific and positive anomalies are dominant over the tropical western Pacific from June to Au- 


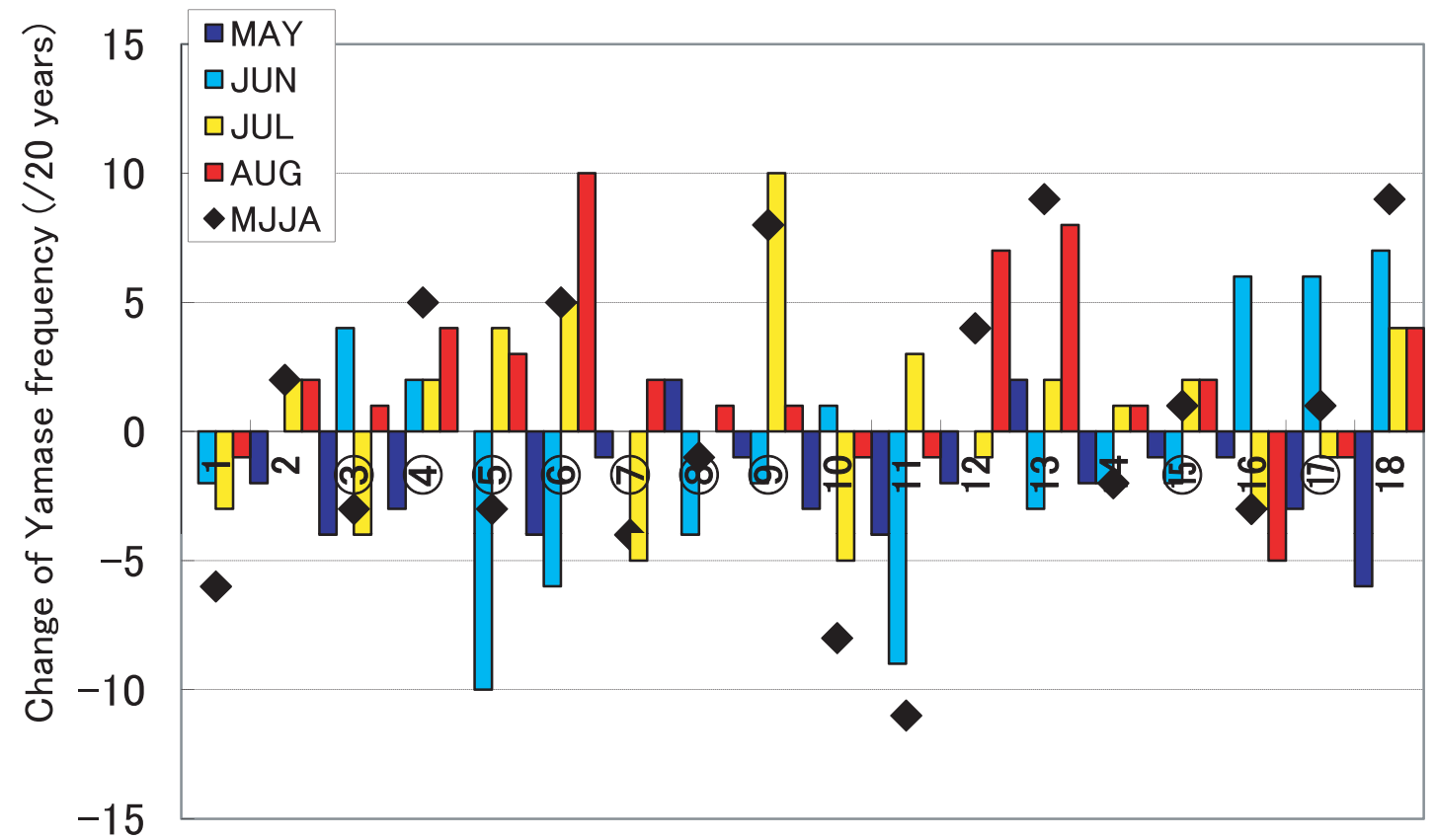

Fig. 5. Future changes in the Yamase frequency per 20 years in the future climate (2081-2100) of the SRES A1B experiments compared with the present-day climate (1981-2000) of the 20C3M experiments for May to August. The bars show the change in the frequency in each month. The black diamonds show the accumulated change from May to August. Numbers in the horizontal axis indicate model IDs shown in Table 1. The numbers of the models belonging to the MME9hi are circled.

gust; these anomalies are clearer than those in MME18. In addition, the north-south dipole anomaly over mid-latitudes of the Pacific in August is clearer, and more than $90 \%$ of the models in MME14 project negative anomalies over the ocean east of Japan.

Models with a negative $\triangle \mathrm{EQ}$-SOI in JJA tend to project increased Yamase frequency (Fig. 6a). The inter-model correlation coefficient between $\triangle \mathrm{EQ}-$ SOI and the projected change in the Yamase frequency is -0.58 for August, but it is low for other months (0.11 in May, 0.22 in June and -0.18 in July). The scatter plot of $\triangle \mathrm{EQ}-\mathrm{SOI}$ in JJA and $\triangle \mathrm{MSLP}$ over the Sea of Okhotsk $\left(140^{\circ} \mathrm{E}-170^{\circ} \mathrm{E}\right.$, $45^{\circ} \mathrm{N}-60^{\circ} \mathrm{N} ; \Delta \mathrm{MSLP} \_\mathrm{OH}$ ) in August (Fig. 6b) and the $\triangle \mathrm{EQ}-\mathrm{SOI}$ and $\triangle \mathrm{MSLP}$ over the area east of Japan $\left(140^{\circ} \mathrm{E}-170^{\circ} \mathrm{E}, 30^{\circ} \mathrm{N}-40^{\circ} \mathrm{N}\right.$; $\left.\triangle \mathrm{MSLP} \_\mathrm{EJ}\right)$ in August (Fig. 6c) shows that models projecting increased Yamase (filled circles) tend to have a negative $\triangle$ MSLP_EJ and a positive $\triangle$ MSLP_OH. The negative $\triangle$ MSLP_EJ is strongly related to a negative $\triangle E Q-S O I$ : the inter-model correlation coefficient between them is 0.74 (Fig. 6c). On the other hand, positive $\triangle \mathrm{MSLP} \_\mathrm{OH}$ cannot be explained by this straightforward linear relationship with the $\Delta$ EQ-SOI (Fig. 6b).

\subsection{Multi-model ensemble of nine models with higher skill}

The CMIP3 models clearly underestimate the Yamase frequency in June and July compared to the reanalysis. Associated with this systematic bias, the models tend to underestimate the Okhotsk high in the MSLP field (Fig. 2a). These biases suggest that current climate models do not have enough skill to represent the Okhotsk high, which may lead to large uncertainty in the projected change in the Yamase frequency in June and July.

We therefore attempt to select models based on their skill in reproducing both the Yamase frequency and the MSLP pattern in the present climate. The defined metric is the average of the skills for the Yamase frequency and the MSLP pattern in June and July. The skill for the Yamase is calculated as follows. First, the monthly errors of the Yamase frequency, referenced to JRA-25, are summed as the root-mean-square error (RMSE) in June and July, and then the value is normalized 

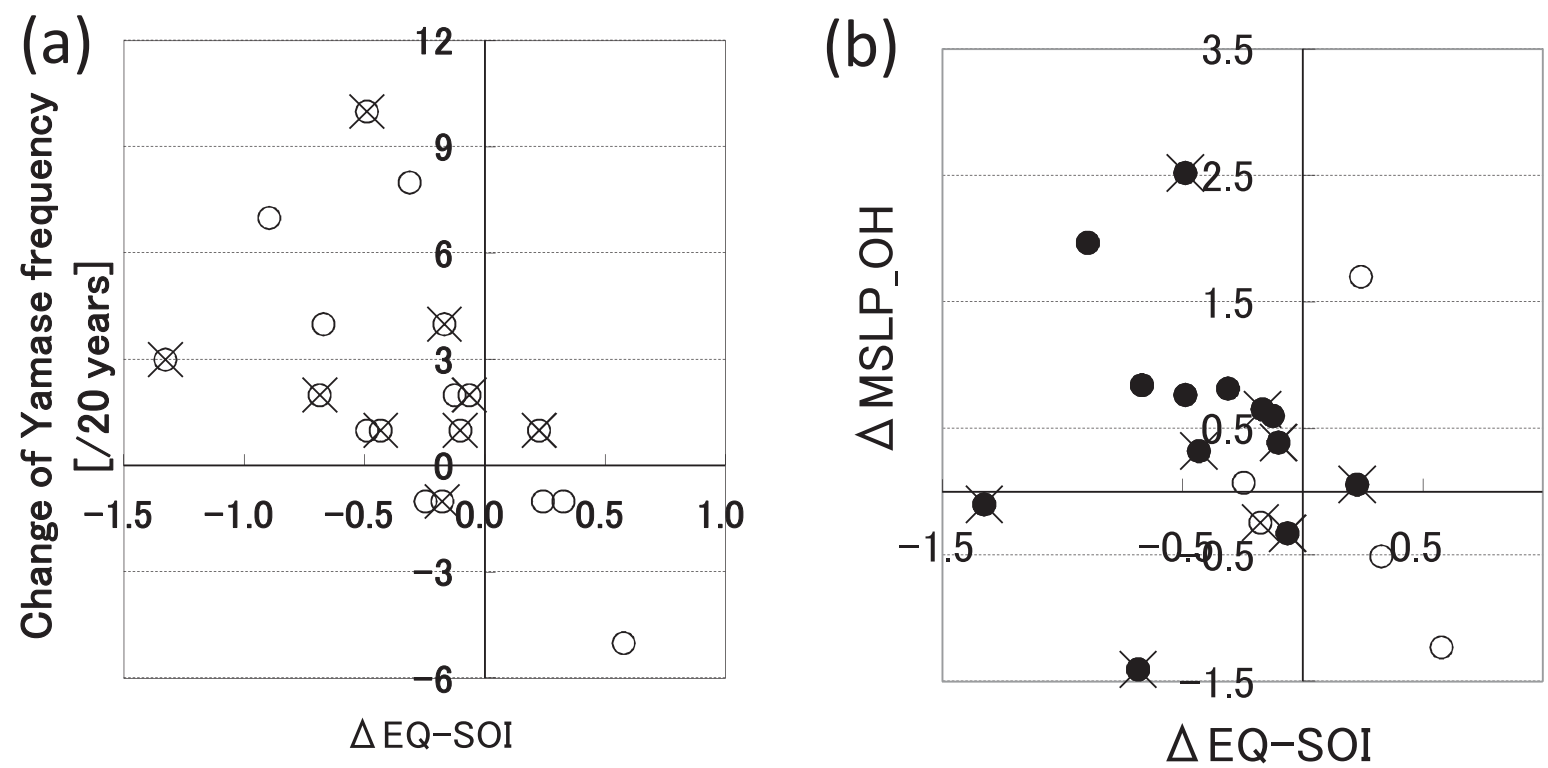

Fig. 6. Scatter plots of (a) future changes in the Yamase frequency in August, (b) future changes in the mean sea level pressure $(\mathrm{hPa})$ over the Sea of Okhotsk $\left(140^{\circ}-\right.$ $170^{\circ} \mathrm{E}, 45^{\circ}-60^{\circ} \mathrm{N}$; MSLP_OH) in August and (c) over the area east of Japan $\left(140^{\circ}-\right.$ $170^{\circ} \mathrm{E}, 30^{\circ}-40^{\circ} \mathrm{N}$; MSLP_EJ) in August versus changes of the EQ-SOI in JJA mean for the all 18 models. Data for models belonging to the MME9hi are shown by as X marks. In (b) and (c), data of models projecting an increased Yamase frequency in August are plotted with filled circles. EQ-SOI is defined as the sea level pressure difference $(\mathrm{hPa})$ between the eastern Pacific $\left(5^{\circ} \mathrm{S}-5^{\circ} \mathrm{N}, 160^{\circ}-80^{\circ} \mathrm{W}\right)$ and the Indo-West Pacific $\left(5^{\circ} \mathrm{S}-5^{\circ} \mathrm{N}, 80^{\circ}-160^{\circ} \mathrm{E}\right)$.

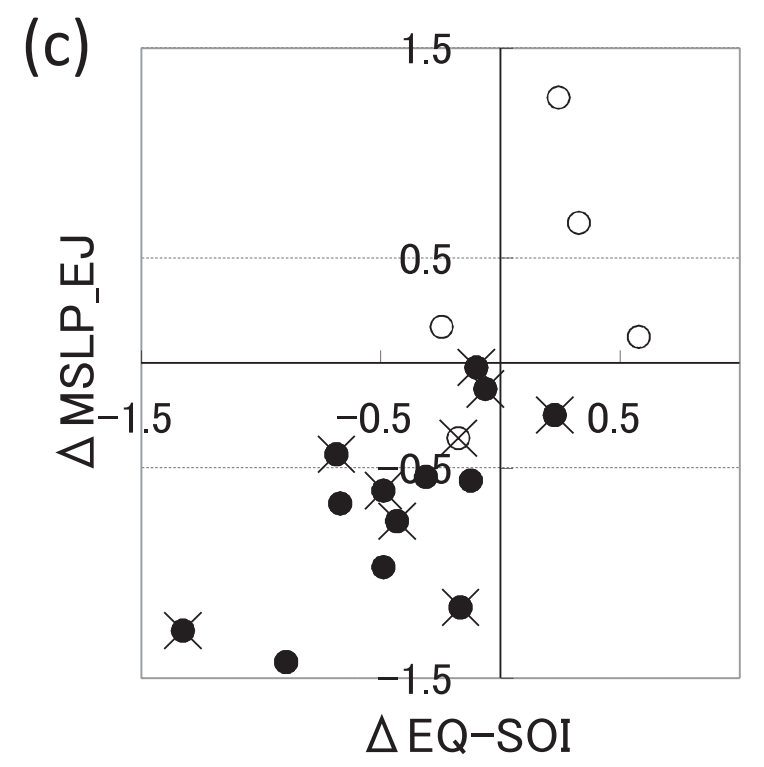

and the sign is adjusted so as to have a positive value for a better model. Skill scores of the MSLP are calculated similarly; the monthly SS_MSLP, listed in Table 1, are averaged in June and July, and then the value is normalized and the sign is adjusted. The calculated metrics are listed in the righthand column of Table 1 . Using this metric, we select nine high-skill models (MME9hi), that is, half of all of the models.

The MME9hi improves the weaker bias of the Okhotsk high in the MME18 (Fig. 2b) and repro-

duces more frequent Yamase and a more realistic seasonal variation of the Yamase frequency than the MME18, although the MME9hi mean slightly overestimates the frequency in August (Table 1 and Fig. 3).

Although changes of the Yamase frequency are inconsistent even among the MME9hi in June and July (Fig. 5), negative anomalies in June over the Sea of Okhotsk and eastern Siberia in the MSLP are contrasted with positive anomalies in July (Fig. 4c), which are unclear in both the MME18 
and MME14 projections. In August, almost all the MME9hi project weakening of the Pacific high over the ocean east of Japan and an increase of the Yamase frequency (Figs. 4c, 5 and 6), consistent with the MME18 projections. Positive MSLP anomalies prevail over the tropical western Pacific from May to August (Fig. 4c). These consistent changes over the tropics and mid-latitudes among the MME9hi may be partly due to consistent signs of the $\triangle E Q-S O I$ : namely, eight models out of MME9hi project a negative $\triangle \mathrm{EQ}-\mathrm{SOI}$ (Table 1).

Kusunoki et al. (2006) showed future changes of the MSLP over the northwestern Pacific as well as the Baiu rainfall in June and July by performing experiments using a $20-\mathrm{km}$ mesh AGCM that successfully reproduced the present climate. The future changes of the MSLP over the Sea of Okhotsk are positive anomaly in July in contrast to negative anomaly in June, although the changes are not statistically significant, which is consistent with this study's MME9hi result.

\section{Discussion}

Weakening of the Walker circulation (i.e., negative $\triangle \mathrm{EQ}-\mathrm{SOI}$ ) is closely related to the weakened Pacific high over the ocean east of Japan and the Yamase increase in August (Fig. 6). Here we show the observed inter-annual relationships between the EQ-SOI and large-scale circulation anomalies in Fig. 7, which are calculated from de-trended monthly data for the period from 1958 to 2007 using NCEP/NCAR reanalysis (Kalnay et al. 1996). For comparison with Fig. 4, the signs of the regression coefficient in Fig. 7 are reversed. In the observed inter-annual variability, negative EQ-SOI is related to a weakened Pacific high over the Pacific and a strengthened and southward-shifted subtropical jet in late boreal summer. This MSLP anomaly pattern is generally similar with the projected changes in late boreal summer (Fig. 4), that is, negative anomalies prevail over the mid-latitude of the Pacific in July and August, with positive anomalies to the north in August. These similarities support a possible connection between the weakening of the Walker circulation and the weakened Pacific high. Tanaka et al. (2005) and Ueda et al. (2006) revealed that many CMIP3 models project weakening of the Asian summer monsoon circulation, as well as weakening of Walker and Hadley circulation. The weakening of the Asian monsoon circulation may also contribute to the robust weakening of the Pacific high over the ocean just east of Japan in August (Fig. 4). Kosaka and Nakamura (2011) suggest that projected changes of large-scale circulations are similar to the Pacific-Japan pattern (Nitta 1987) through investigation of the CMIP3 multimodels.

Even though many models project increase of the Yamase in August, future strengthening of the Okhotsk high in the MSLP in August seems not to be significant (Fig. 4). We think that the projected weakened Pacific high makes a certain contribution to the increased Yamase in the model results. Kanno (2004) and Yasunaka and Hanawa (2006) showed a north-south surface pressure gradient over northeastern Japan is strongly related to the Yamase and resultant Yamase-type anomaly distribution in terms of temperature and sunshine duration. Tachibana et al (2004) indicated that both the development of the ridge over eastern Siberia and the weakness of the Pacific high over the ocean east of northern Japan influence the development of the Okhotsk high from investigation of the observed inter-annual variability. It is also another possibility that the blocking activity over eastern Siberia may increase in the future climate, as suggested by Arai and Kimoto (2008). If so, this leads to enhancement of the Okhotsk high, increasing the Yamase frequency even though the MSLP change is unclear.

We should discuss not only tropical factors but also extra-tropical factors on the projected change of the Yamase frequency. In May, most models project decrease of the Yamase frequency and negative anomalies over high latitudes in the MSLP. Figure 8 shows the MSLP anomaly in January through May. The negative anomalies over the high latitudes in May begin from the boreal winter, and this anomaly pattern is similar to the positive phase of the Northern Annular Mode (NAM) or the Arctic Oscillation (AO), which are known to be response of the climate system to global warming (e.g., Miller et al. 2006). The negative anomalies persist until early boreal summer over the area north of Japan, strengthening westerly winds and probably attributing to the projected decrease of the Yamase frequency in May.

Land surface warming has been considered to be an important factor for enhancement of the Okhotsk high in the climate change caused by global warming as well as in the inter-annual variability (Kimoto 2005; Arai and Kimoto 2005, 2008). Kimoto (2005) demonstrates that Eurasian 
(a) SLP
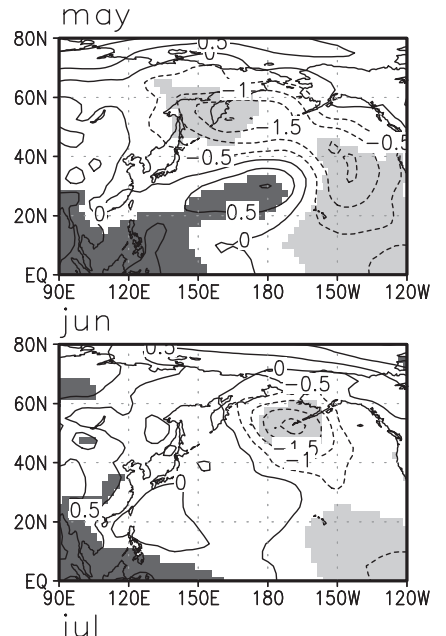

jul

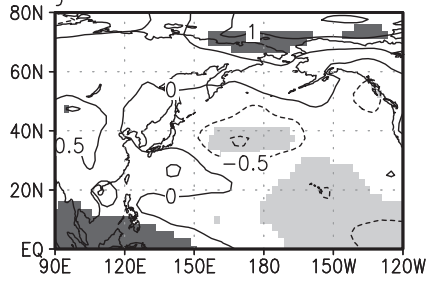

aug

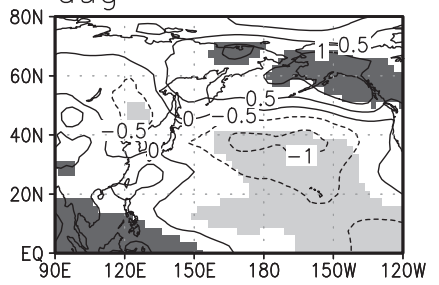

(b) $U 200$
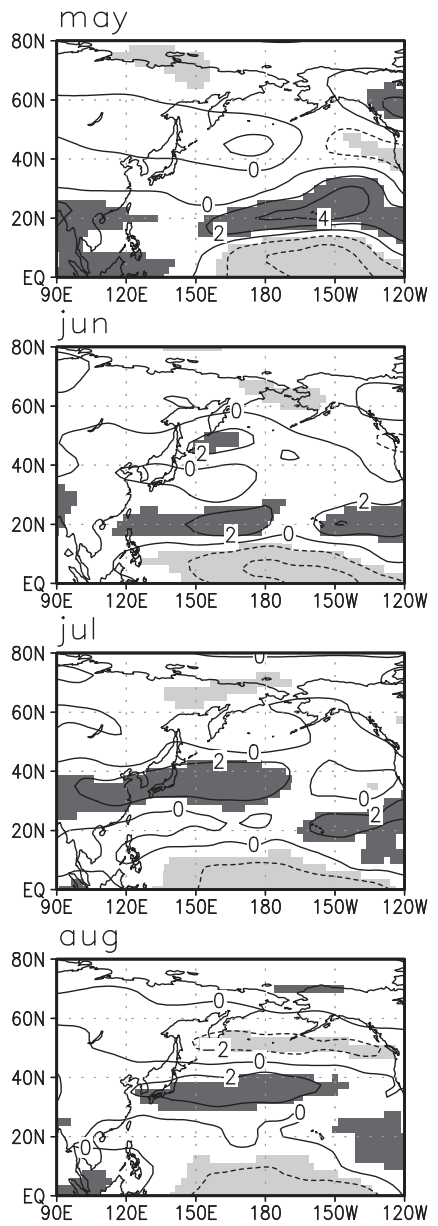

Fig. 7. Observed monthly (a) sea level pressure and (b) $200 \mathrm{hPa}$ zonal wind regressed on the EQ-SOI, based on NCEP/NCAR (1958-2007). For comparison with Fig. 4, the signs of the regression coefficient are reversed. Shading indicates that the correlation coefficient is significant at the $5 \%$ level. The contour intervals are (a) $0.5 \mathrm{hPa}$ and (b) $2 \mathrm{~m} / \mathrm{s}$, respectively. The sea level pressure field and the EQ-SOI are de-trended for the analyzed period.

continental surface warming contributes to the strengthening of an anticyclone over high latitudes of the Pacific, through an AGCM experiment. We briefly examine inter-model relationships between land surface warming over Siberia and enhancement of the Okhotsk high by a simple method, based on MME18. Correlation coefficients between surface air temperature changes over the land of Siberia $\left(60^{\circ}-180^{\circ} \mathrm{E}, \quad 40^{\circ}-70^{\circ} \mathrm{N} ; \quad \Delta \mathrm{SATMP} S \mathrm{SB}\right)$ in JJA and $\triangle \mathrm{MSLP} \mathrm{OH}_{\mathrm{O}}$ in each month based on MME18 are $0.15,0.11,-0.44,0.32$, and 0.06 for May, June, July, August, JJA, respectively. In the case of the lagged relationship between $\triangle \mathrm{STAMP}$ SB in March through May (MAM) mean and $\triangle \mathrm{MSLP}$ _OH in each month, the correlation coefficients are $0.06,0.03,-0.35,0.55$, and 0.19 for May, June, July, August, JJA, respectively. Only the relationship between $\triangle \mathrm{SATMP}$ SB in MAM and $\triangle \mathrm{MSLP}$ _OH in August shows a statistically significant at the 5\% level. As for an investigation based on MME9hi, no coefficients reach to the significance level. Further elaborate investigation is needed to clarify the continental warming on the Okhotsk high and the Yamase.

The changes of the MSLP projected by the MME9hi show negative anomalies in June in contrast to positive anomalies in July over the Sea of Okhotsk and eastern Siberia in the MSLP field, 


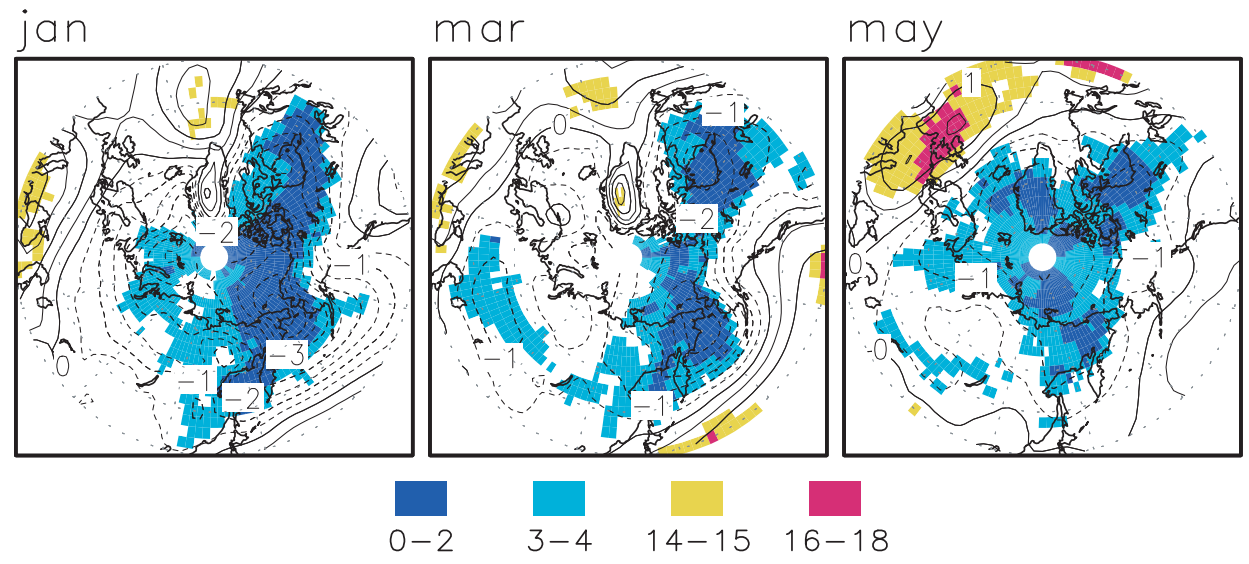

Fig. 8. Same as Fig. 4a except for over high latitudes in the northern hemisphere in January, March and May.

which are unclear for the MME18 and MME14 (Fig. 4). These anomalies appearing near the Sea of Okhotsk only in the MME9hi are worth noting, because the metric to select the MME9hi reflects model performance of reproducing the Okhotsk high to some degree. Further studies are necessary for understanding these interesting changes. It is generally pointed out that the Okhotsk high develops associated with a blocking anticyclone in the upper troposphere (Nakamura and Fukamachi 2004). Tachibana et al. (2004) discusses that the development of the Okhotsk high restricted in the lower troposphere may be influenced by air-sea interaction through occurrence of low-level clouds and marine fog. We should further assess the Okhotsk high reproduced in the climate models with focus on such phenomena.

\section{Summary}

This study investigates future changes in the frequency of the Yamase occurrences by analyzing 18 AOGCM experiments in CMIP3 archives for May to August. In the present-day climate, the MME18 mean modestly reproduces seasonal variation of the Yamase frequency, although each model generally underestimates the Yamase frequency compared to the reanalysis data and large differences are seen among the models. The models show a systematic bias toward a strong Pacific high and a weak Okhotsk high.

In the future climate, most models project increases of the Yamase frequency in August in contrast to decreases of the frequency in May, whereas projected frequency changes in June, July and
MJJA are inconsistent among the MME18. Intermodel comparison suggests that weakening of mean tropical circulation, including the Walker circulation, may contribute to the increased Yamase frequency in August. A projection employing only nine of the models with higher skill (MME9hi), based on a defined metric, is also tried. Although changes of the Yamase frequency are inconsistent even among the MME9hi in June and July, negative anomalies in June over the Sea of Okhotsk and eastern Siberia in the MSLP are contrasted with positive anomalies in July, which are unclear in the MME18 projections. In August, almost all the MME9hi project increase of the Yamase frequency, consistent with the MME18 projections.

Our study shows that the Yamase occurrences will increase in August in the future climate. This change corresponds to a delay of the Yamase season, because in the present climate the Yamase blow most frequently in June and July. Kitoh and Uchiyama (2006) indicated a delay in the Baiu rain withdrawal by an analysis using fifteen CMIP3 model simulations (almost the same dataset analyzed in this study). Thus, the CMIP3 models project that not only the Baiu season observed over southern Japan but also the Yamase season observed over northeastern Japan will be delayed in the future climate. Anomalous weather associated with the Yamase for late July to mid August, corresponding to the high summer season over northern Japan, has particularly large impact on agriculture and society, therefore the delay of the seasonal march projected by the CMIP3 models is noteworthy. 


\section{Acknowledgements}

This work is supported by the Global Environment Research Fund (S-5-2). We acknowledge the modeling groups, the Program for Climate Model Diagnosis and Intercomparison (PCMDI) and the WCRP's Working Group on Coupled Modeling (WGCM) for their roles in making available the WCRP CMIP3 multi-model dataset. Support of this dataset is provided by the Office of Science, U.S. Department of Energy. We also express our gratitude to the "Data Integration and Analysis System" Fund for National Key Technology from the Ministry of Education, Culture, Sports, Science and Technology, Japan, for providing us with an invaluable environment for a mass data handling. We appreciate various valuable comments from Dr. T. Ose of MRI, and technical support from Kanako Aadachi in drawing Fig. 1. We also thank the two anonymous reviewers and the editor for useful comments.

\section{References}

Arai, M., and M. Kimoto, 2005: Relationship between springtime surface temperature and early summer blocking activity over Siberia. J. Meteor. Soc. Japan, 83, 261-267.

Arai, M., and M. Kimoto, 2008: Simulated interannual variation in summertime atmospheric circulation associated with the East Asian monsoon. Clim. Dyn., 31, 435-447.

Endo, H., 2008: Yamase. In: Study of climate change over Tohoku district due to global warming, Technical Reports of the Meteorological Research Institute. 52, 27-48 (in Japanese).

Giorgi, F., and L. O. Mearns, 2002: Calculation of average, uncertainty range, and reliability of regional climate changes from AOGCM simulations via the "Reliability Ensemble Average" (REA) method. J. Climate, 15, 1141-1158.

Inoue, T., and H. Ueda, 2011: Delay of the first transition of Asian summer monsoon under global warming condition. SOLA, 7, 81-84.

IPCC, 2007: Climate Change 2007: The Physical Science Basis. Contribution of Working Group I to the Fourth Assessment Report of the Intergovernmental Panel on Climate Change. Solomon, S. et al., Eds., Cambridge University Press, $996 \mathrm{pp}$.

Kalnay, E., M. Kanamitsu, R. Kistler, W. Collins, D. Deaven, L. Gandin, M. Iredell, S. Saha, G. White, J. Woollen, Y. Zhu, M. Chelliah, W. Ebisuzaki, W. Higgins, J. Janowiak, K. C. Mo, C. Ropelewski, J. Wang, A. Leetmaa, R. Reynolds, R. Jenne, and D. Joseph, 1996: The NCEP/NCAR 40-year reanalysis project. Bull. Amer. Meteor. Soc., 77, 437-471.

Kanno, H., 1993: Differences of temperature and humidity between Yamase and sea breeze and their seasonal variations at Hachinohe in Aomori Prefecture. Tenki, 40, 751-757 (in Japanese).

Kanno, H., 1997: Classification of the Yamase (cold northeasterly wind around northeastern Japan) based upon its air-mass vertical structures. J. Meteor. Soc. Japan, 75, 1053-1071.

Kanno, H., 2004: Five-year cycle of north-south pressure difference as an index of summer weather in northern Japan from 1982 onwards. J. Meteor. Soc. Japan, 82, 711-724.

Kimoto, M., 2005: Simulated change of the east Asian circulation under global warming scenario. Geophys. Res. Lett., 32, L16701, doi:10.1029/ 2005 GL023383.

Kitoh, A., and T. Uchiyama, 2006: Changes in onset and withdrawal of the East Asian summer rainy season by multi-model global warming experiments. $J$. Meteor. Soc. Japan, 84, 247-258.

Knutson, T. R., and S. Manabe, 1995: Time-mean response over the tropical Pacific to increased $\mathrm{CO}_{2}$ in a coupled ocean-atmosphere model. J. Climate, 8, 2181-2199.

Kodama, Y.-M., 1997: Airmass transformation of the Yamase air-flow in the summer of 1993. J. Meteor. Soc. Japan, 75, 737-751.

Kosaka, Y., and H. Nakamura, 2011: Dominant mode of climate variability, inter-model diversity and projected future changes over the summertime western North Pacific simulated in the CMIP3 models. J. Climate, 24, 3935-3955.

Kurihara, K., K. Ishihara, H. Sasaki, Y. Fukuyama, H. Saitou, I. Takayabu, K. Murazaki, Y. Sato, S. Yukimoto, and A. Noda, 2005: Projection of climatic change over Japan due to global warming by highresolution regional climate model in MRI. SOLA, 1, 97-100.

Kusunoki, S., and R. Mizuta, 2008: Future changes in the Baiu rain band projected by a $20-\mathrm{km}$ mesh global atmospheric model: sea surface temperature dependance. SOLA, 4, 85-88.

Kusunoki, S., J. Yoshimura, H. Yoshimura, A. Noda, K. Oouchi, and R. Mizuta, 2006: Change of Baiu rain band in global warming projection by an atmospheric general circulation model with a $20-\mathrm{km}$ grid size. J. Meteor. Soc. Japan, 84, 581-611.

Miller, R. L., G. A. Schmidt, and D. T. Shindell, 2006: Forced annular variations in the 20th century IPCC AR4 simulations. J. Geophys. Res., 111, D18101, doi:10.1029/2005JD006323.

Min, S.-K., E.-H. Park, and W.-T. Kwon, 2004: Future projections of East Asian climate change from multi-AOGCM ensembles of IPCC SRES scenario 
simulations. J. Meteor. Soc. Japan, 82, 11871211.

Nakamura, H., and T. Fukamachi, 2004: Evolution and dymnamics of summertime blocking over the Far East and the associated surface Okhotsk high. Quart. J. Roy. Meteor. Soc., 130, 1213-1233.

Ninomiya, K., and H. Mizuno, 1985: Anomalous cold spell in summer over northeastern Japan caused by northeasterly wind from polar maritime airmass. Part1. EOF anslysis of temperature variation in relation to the large-scale situation causing the cold summer. J. Meteor. Soc. Japan, 63, 845857.

Nitta, T., 1987: Convective activities in the tropical western Pacific and their impact on the northern hemisphere summer circulation. J. Meteor. Soc. Japan, 65, 373-390.

Onogi, K., J. Tsutsui, H. Koide, M. Sakamoto, S. Kobayashi, H. Hatsushika, T. Matsumoto, N. Yamazaki, H. Kamahori, K. Takahashi, S. Kadokura, K. Wada, K. Kato, R. Oyama, T. Ose, N. Mannoji, and R. Taira, 2007: The JRA-25 reanalysis. J. Meteor. Soc. Japan, 85, 369-432.

Tachibana, Y., T. Iwamoto, M. Ogi, and Y. Watanabe, 2004: Abnormal meridional temperature gradient and its relation to the Okhotsk high. J. Meteor. Soc. Japan, 82, 1399-1415.

Takai, H., H. Kawamura, and O. Isoguchi, 2006: Characteristics of the Yamase winds over oceans around Japan observed by the scatterometer de- rived ocean surface vector wind. J. Meteor. Soc. Japan, 84, 365-373.

Tanaka, H. L., N. Ishizaki, and D. Nohara, 2005: Intercomparison of the intensities and trends of Hadley, Walker and monsoon circulations in the global warming projections. SOLA, 1, 77-80.

Taylor, K. E., 2001: Summarizing multiple aspects of model performance in a single diagram. J. Geophys. Res., 106, 7183-7192.

Ueda, H., A. Iwai, K. Kuwako, and M. E. Hori, 2006: Impact of anthropogenic forcing on the Asian summer monsoon as simulated by eight GCMs. Geophys. Res. Lett., 33, L06703, doi:10.1029/ 2005 GL025336.

Vecchi, G. A., B. J. Soden, A. T. Wittenberg, I. M. Held, A. Leetmaa, and M. J. Harrison, 2006: Weakening of tropical Pacific atmospheric circulation due to anthropogenic forcing. Nature, 441, 73-76.

Wakabayashi, S., and R. Kawamura, 2004: Extraction of major teleconnection patterns possibly associated with the anomalous summer climate in Japan. $J$. Meteor. Soc. Japan, 82, 1577-1588.

Wang, Y., B. Wang, and J.-H. Oh, 2001: Impact of the preceding El Nino on the East Asian summer atmospheric circulation. J. Meteor. Soc. Japan, 79, 575-588.

Yasunaka, S., and K. Hanawa, 2006: Interannual summer temperature variations over Japan and their relation to large-scale atmospheric circulation field. J. Meteor. Soc. Japan, 84, 641-652. 